\title{
Designing real-world laboratories for sustainable urban transformation: addressing ambiguous roles and expectations in transdisciplinary teams
}

\author{
Sandra Huning ${ }^{1}$ (1) C. Räuchle ${ }^{2} \cdot$ M. Fuchs $^{1}$
}

Received: 11 January 2021 / Accepted: 7 June 2021 / Published online: 19 June 2021

(c) The Author(s) 2021

\begin{abstract}
This paper reflects upon the potential of real-world laboratories (RWLs) to promote sustainable urban development. RWLs strive for knowledge production through collective action in experimental settings. Their implementation in urban studies faces two major challenges: (1) the ambiguity of roles university researchers need to fill, and (2) the variety of expectations among team members from different institutional backgrounds. Based on research in one trans-European and three German RWLs, we propose a stronger focus on team development to help researchers in RWLs address these challenges more systematically. In particular, this means support in terms of resources and infrastructure (time, space, and training). We argue that the improvement of RWL team performance has great impact on the potentials of RWLs in transformative urban studies. Thus, the article contributes to the ongoing debate on the city as a laboratory and site of experimentation in times of multiple crises.
\end{abstract}

Keywords Transdisciplinary research $\cdot$ Urban transformation $\cdot$ Real-world laboratory $\cdot$ Participatory research $\cdot$ Sustainable transformation $\cdot$ Team development

\section{Introduction: transdisciplinary and transformative research in real-world laboratories-expectations and challenges}

Cities have been facing an increasing multitude of social, environmental, and economic crises over the past years. These crises have had led to a search for new methods and new forms of cooperation to enable and promote urban transformation and sustainable development. A broad range of actors from politics, civil society, and academia has been joining efforts in search for transformative and sustainable strategies to solve the 'wicked problems' urban planners

Handled by Peter John Marcotullio, Hunter College Geography, United States.

Sandra Huning

Sandra.huning@tu-dortmund.de

1 Faculty of Spatial Planning, Chair of Urban and Regional Sociology, TU Dortmund University, Dortmund 44227, Germany

2 Institute for Geographical Science, Free University Berlin, Berlin, Germany and politicians are confronted with (Brown et al. 2010). The complex challenges for cities call for a transformative and transdisciplinary science, which benefits from knowledge integration and from recursive and mutual learning of urban actors from different institutional backgrounds.

Transdisciplinary research has two main components: (1) a 'close relation to the concept of transformation' and (2) 'the co-creation of knowledge, that means, the process of research includes not only scientific actors but also representatives of politics, the private sector and civil society [who] possess agency for transforming knowledge into collective action' (Renn 2018, p. 1). It fosters transformation by developing and implementing solutions to urban challenges and generating generalizable knowledge for sustainable action that can be either transferred to other contexts or scaled up for system-wide application (Luederitz et al. 2017; Schäpke et al. 2018). This type of research has been called 'inherently inefficient' due to, e.g., different performance criteria and levels of commitment, but it is also expected to 'produce high social and academic impact when undertaken properly' (Gaziulusoy et al. 2016, p. 57; 63).

For more than a decade, there has been a renewed interest in the city as a laboratory and as experimental ground 
(Scholl and Kemp 2016). Derived from earlier experiences in sustainability studies, a new methodological approach called the real-world laboratory (RWL) has entered the field of transdisciplinary urban studies (Bulkeley et al. 2019; Schneidewind 2014; Wanner et al. 2018). It relates to earlier research strategies of stakeholder and citizen engagement such as Participatory Action Research (PAR, e.g., Kemmis and McTaggart 2005; Ozanne and Saatcioglu 2008) or intervention research (e.g., Thomas and Rothman 2013), which focus on participation, empowerment, and capacity building of different stakeholder groups (Wanner et al. 2018). Some authors use the 'lab' terminology metaphorically to describe cities as bustling places of intense social life. In addition, an increasing number of researchers sees cities as places to experiment with novel approaches of knowledge production in situ and, with that, have a specific methodological understanding of 'urban laboratories' (Karvonen and van Heur 2014). Thus, lab approaches reflect an 'experimental turn' in social sciences (Schneidewind 2014, p. 2). ${ }^{1}$

Transdisciplinary RWLs that strive for urban transformation differ from those in other disciplines and contexts. In this paper, we address two challenges, which result from the RWL ideal of cyclical research processes open to constant adaptations, unintended consequences, and new actors. Strategies, stakeholders, roles, and outcomes may change during the research process leading to new directions and detours that were unpredictable in the beginning. First, the objective of urban transformation implies that university researchers may have to take over additional roles such as knowledge broker, change agent, or facilitator, which they may not be prepared to do. Second, experiments, successful or not, always leave traces in urban space, so that actors from public institutions and civil society are not only concerned with the search for problem solutions, but also with, for example, their (political) effects on long-term stakeholder relations. Consequently, expectations differ within a research team. Researchers need to address both challenges, as they affect team development and performance of urban RWLs and their interpretation of success or failure.

Based on research in four urban RWL research projects, which we introduce in more detail below, we discuss and illustrate how these two challenges play out and potentially put re-search processes aiming at urban transformation at risk. In search of strategies to address them, we scrutinize literature on science of team science and group development,

\footnotetext{
${ }^{1}$ In RWL literature, authors describe a broad variety of experimental arrangements between academia, policy and business: (urban) living labs, transition labs, sustainable living labs, innovations labs, and design labs, to name just a few beside the RWL (Schäpke et al. 2017; Scholl and Kemp 2016). Differences concern, e.g., the research traditions they refer to, their overarching goals and the corresponding governance arrangements (Schäpke et al. 2018).
}

which suggests that consequent phases of team building and evaluation are necessary for (research) teams to pursue common goals. Studies on the science of team science emphasize the influence of contextual (e.g., interpersonal, organizational) factors on how teams connect and collaborate and, in the end, on the process and outcomes of transdisciplinary teams (see, e.g., Stokols et al. 2008; Börner et al. 2010). They also highlight the need for further research on this impact.

Our cases show, however, that RWLs necessarily produce 'unsettled teams', particularly in the urban studies context, which affects the definition of roles and the management of (fluid) expectations. Against the background of several typical situations where this has come to the fore in our RWLs, we argue that transdisciplinary teams in general and urban RWL teams in particular need to devote more resources to team development processes and to guide 'unsettled' transdisciplinary teams through cyclical RWL processes. While 'learning by doing' may be an important way to gather embodied knowledge on (and in) RWL research, we argue that transdisciplinary teams in RWLs need more time, space and skills for reflecting team development, possibly including professional support and infrastructures. In the end, we are convinced that this will promote better transdisciplinary cooperation and thus lead to more transformative knowledge particularly needed in times of urban crisis.

In "Challenges for RWLs in urban settings", we elaborate on the ideal of RWLs and the challenges we identify for urban studies. Section "Materials and methods" holds the materials and methods for this paper. In "Ambiguous roles and expectations: experiences from four RWL-based research projects", we present three ideal-typical research situations, which illustrate that the two challenges deserve more attention in urban studies than they have received in RWL literature so far. In "Discussion: organizing transdisciplinary teamwork in RWLs", we relate them to team development literature, which analyses different phases of team building and certain prerequisites for successful team performance. In "Outlook: the potential of RWLs in transformative urban studies", we conclude the importance of team development for success or failure of transformative urban RWLs and present an outlook.

\section{Challenges for RWLs in urban settings}

At the interface of transformative and transdisciplinary research, RWLs aim at producing socially robust knowledge, i.e., they integrate knowledge from various scientific and societal sources (Nowotny et al. 2011). They are part of a more general move towards experimental, transdisciplinary research agendas (Karvonen and van Heur 2014) and thus different from more traditional urban research with more or 


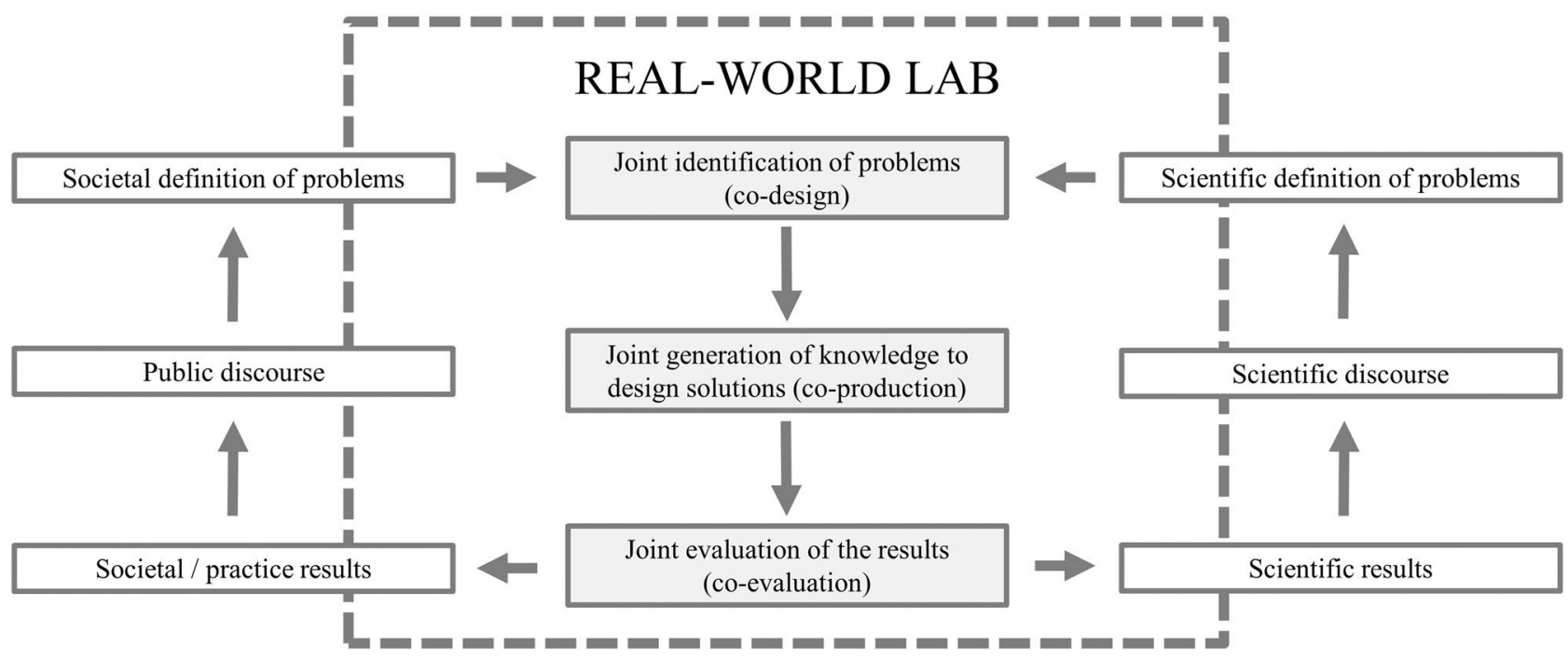

Fig. 1 Ideal-typical RWL model; own figure based on Sieber and Gülleken (2018)

less clear objectives and fixed teams. According to Kanning (2018, p. 10), transdisciplinary RWLs strive for systematic, target and transformative knowledge through the codesign and co-production of knowledge (see an ideal-typical process model in Fig. 1); they are participatory and include permanent self-reflection and learning processes. To some degree, they take up 1960s/70s action research, which emerged from a critique of positivism and considered social science as normative, political, and potentially emancipatory. Action research was designed as dialogue between scientists and practitioners; democratic participation and empowerment were key (Fricke 2014) to understand and change social realities. Key critique, however, was that 1970s action research was more activism than research (von Unger 2014, p. 3). To avoid this dilemma, particularly university researchers need to define their roles clearly, as we discuss in more detail below.

In RWLs, team constellations depend on the research objectives (Kanning 2018, p. 10). According to the RWL actor model by Seebacher et al. (2018, p. 156), there are three types of actors' involvement: (1) Core team members are responsible for the overall management and realization of the RWL process. (2) Engaged stakeholders contribute time, money, or knowledge to specific interventions on a regular basis. (3) Loosely connected stakeholders only occasionally participate in RWL activities (see an ideal-typical actor model in Fig. 2). Hilger et al. (2018) argue that establishing a transdisciplinary team is the starting point for every RWL. In urban studies, RWLs members come from universities and other research institutions, public (planning) administration, local business associations or civil society; they may or may not have an academic background, and their motivation to do research in a particular project may be very different from academic researchers. This entails (at least) two major challenges for RWL-based research: ambiguous roles for researchers beyond their traditional role of reflective scientist, and different expectations among team members in terms of cooperation and RWL results. We will explicate the state of re-search with regard to these challenges in the following sections.

\section{Ambiguous roles for researchers in RWL research settings}

In transdisciplinary research in general, and RWLs in particular, traditional role models for researchers and non-academic actors must be constantly renegotiated (Pohl et al. 2010; Wittmayer and Schäpke 2014). Actors in RWLs may assume a multiplicity of roles during lab activities. These roles depend on the particular situation, but also on conditions such as the group set-up, individual experience and knowledge, available resources, and expectations (Hilger et al. 2018; Pohl et al. 2010). Understood as social constructions, roles can be adapted and negotiated and thus change over time. A person can fulfil several roles simultaneously, and several team members can fill out the same roles at the same time (Stoecker 1999; Wittmayer and Schäpke 2014; Wittmayer et al. 2017). According to Nyström et al. (2014), the role of an actor is created by his*her individual action and objectives and by the reactions of others (Nyström et al. 2014). In search for transformation, stakeholders need to adapt to and remain flexible in manifold situations and to be open to take over new, maybe unexpected roles. This 'lack of clarity regarding roles and responsibilities within the 


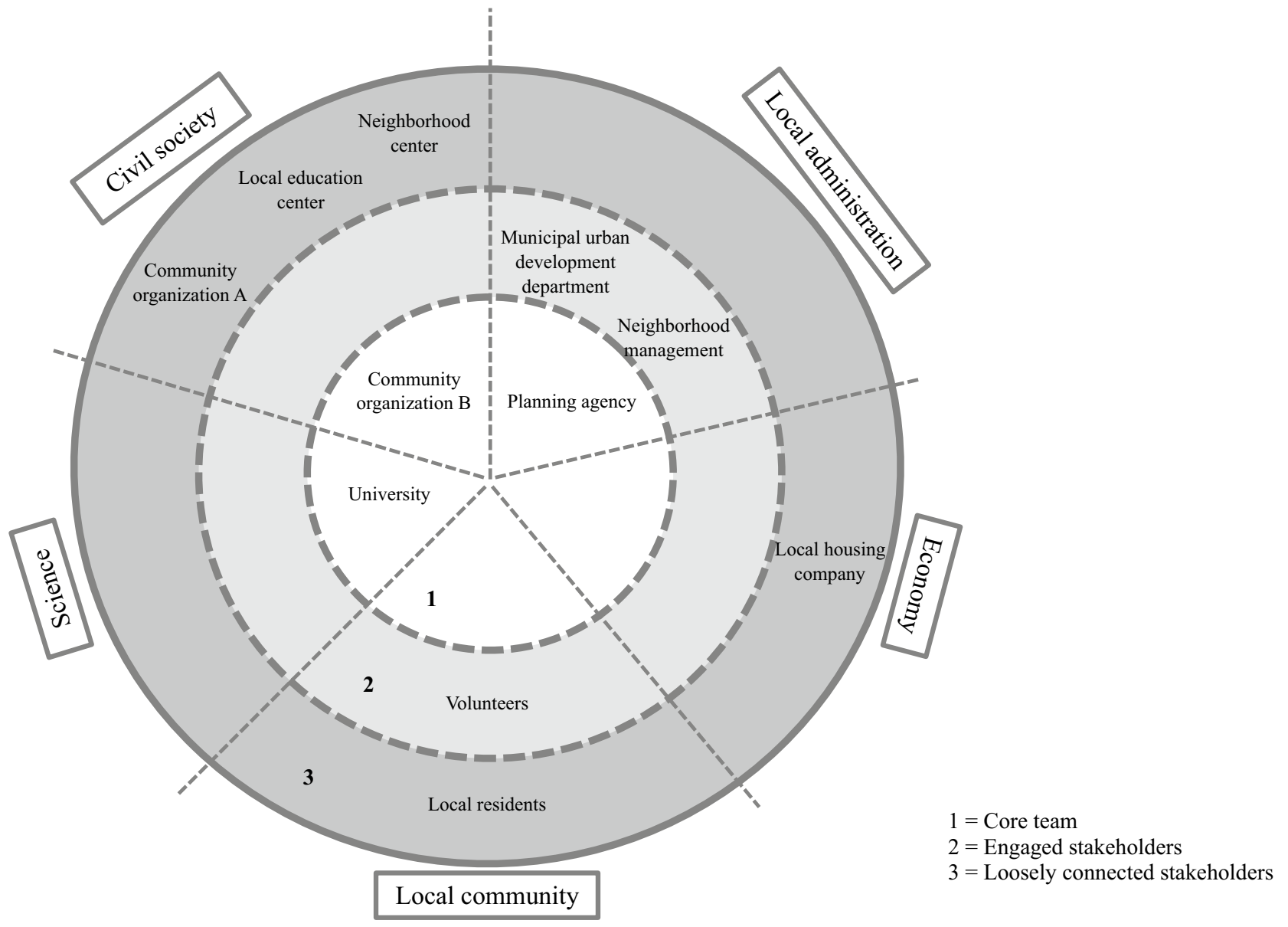

Fig. 2 Ideal-typical RWL actor model; own figure based on Seebacher et al. (2018, p. 156)

research team' (Gaziulusoy et al. 2016, p. 60) is an important challenge for transdisciplinary projects.

While the multiplicity of roles concerns-at least in principle-all RWL participants, it particularly concerns university researchers, who are often in the lead of the RWL and thus particularly called upon to organize the collaborative RWL process. According to process-oriented ${ }^{2}$ sustainability science, there are five ideal-typical roles for academics (Hilger et al. 2018; Pohl et al. 2010; Wittmayer and Schäpke 2014):

(1) The change agent who strives for capacity building and the implementation of interventions;

\footnotetext{
${ }^{2}$ In contrast to the knowledge-first approach, in which scientists traditionally contribute with their scientific expertise and social actors contribute goals and values, the process-oriented approach focuses on their collaboration, co-design, co-production, and co-creation in terms of knowledge, objectives and values (Wittmayer and Schäpke 2014).
}

(2) The knowledge broker or knowledge intermediary who mediates between different perspectives and styles of thinking (cf. Padmanabhan 2017);

(3) The reflective scientist who provides scientific expertise (most consistent with conventional researcher roles);

(4) The (self-)reflexive scientist who-detached from practice-constantly reflects on the influence of positionalities, power dynamics, and research relations for the research process and corresponding results; and

(5) The process facilitator who initiates, forms and promotes collaboration, encourages all participants to express their views and enables transdisciplinary integration of knowledge.

The specific challenges of labs may create frictions among actors, e.g., when some group members understand 
the researchers' role as descriptive analysts and knowledge providers, while others consider them as activists 'establishing, facilitating and participating in mechanisms or dialogues for change' (Miller 2013, p. 287; cf. Kajikawa 2008; Wiek et al. 2012). At the same time, it is a difficult task to understand which role to fulfil at a certain moment, and the necessary skills extend the skills needed in more traditional empirical research settings.

\section{Management of motivations and expectations}

Researchers from academia and other institutions not only take on different and changing roles during the research process. They also join the RWL with diverse motivations and expectations, according to their respective institutional (action) logic, their interest in the project, the strategy of integration into the process, the challenges and their responses to these challenges (Engels and Walz 2018, pp. 41-43). Engels and Walz (2018, pp. 43-44) propose five RWL co-design strategies to address this multi-perspectivity: (1) ensure mutual learning between team members, (2) create ownership and avoid take-overs among them, (3) develop and maintain trustful relations, (4) engage with citizens, and (5) create room for change. According to Wanner et al. (2018, p. 101), '[f]acing different knowledges, interests and activities of science and practice, clearly defined roles are crucial in RWL'. Ideally, the better all team members communicate their goals from the very beginning, the better the different expectations can be reconciled, and conflicts be avoided (also see Singer-Brodowski et al. 2017, p. 62). However, this clear definition of roles is often a problem in RWL processes. For example, not all team members can take independent decisions. They represent specific institutions and have individual responsibilities and power, social and professional competencies and (career) ambitions. Other (powerful) actors may exert their influence 'behind the scenes'. At universities, for example, professors may supervise their staff, and define targets and standards, without taking part themselves in every team meeting or being involved in the organization of everyday matters. Team members from public administrations can also not act autonomously; instead, department heads and colleagues do have an indirect influence on what is happening in the lab, as do local politicians who determine political frameworks. Team members from civil society often represent an association or an initiative and thus also depend on others. In urban RWL settings, where interventions have real-world consequences, these factors are much more influential than in other research settings. Some of them are not—and cannot be made—explicit, even if explicit agreements on task sharing exist (Padmanabhan 2017, p. 19). The interpretative schemes of different actors may look similar but still differ. Conventions that may seem self-evident to one actor may require explanations for everyone else, concerning, e.g., timeframes, availabilities, response speed, hierarchies, etc. (also see Gaziulusoy et al. 2016, p. 60).

Apart from the factors that may lead to communication failures, there may also be different expectations in terms of outcomes that cannot be easily reconciled. RWLs are expected to produce 'successful solutions' for real-world problems in a reasonable amount of time, which 'pushes science to a certain extent toward "solutionism"" (Rogga et al. 2018 , p. 20). Professionals who invest time and energy into research, often without any external reward or remuneration, may become impatient if researchers keep reflecting at a conceptual level for an-in their eyes-'unnecessary' amount of time without producing handy solutions that are easily applicable to their problems.

\section{Materials and methods}

This paper is based on four research projects the authors were or still are involved in. Each set-up one or more RWLs in German cities and/or region, one as part of a trans-European program.

Case A is a 3-year RWL project located in three German cities. As the growing diversity in cities calls for new approaches to enhance social cohesion, the project analyses the role of urban open spaces for fostering communities of dialogue and neighborly solidarity. To this purpose, it tests innovative methods of cooperative open space development in three so-called 'arrival neighborhoods' (Saunders 2010), which are characterized by social deprivation, migration, and high housing density. The core team of the here-discussed lab (which is one of three in the total project) consists of one scientist, two urban planners, and two representatives of a local urban gardening association. Additional partners are local professionals from community development, housing associations, and the city administration.

Case B was a 3-year research and innovation project, which aimed to develop an integrated, evidence-based strategy for air pollution control to reduce urban air pollution and the negative impacts of climate change. Living labs in six European cities were established, one of them-the herediscussed lab-focused on a low-threshold urban design and planning intervention in a German city. Trees in mobile pots ('wandering trees') were collectively moved through neighborhoods and schools to enhance acceptance for public green and demonstrate its benefits for human health. In this lab, two planning researchers from a university and three city administrators from the case study city worked together in the core team. During the process, further administrators, neighborhood managers, local businesses and citizens temporarily joined the lab and its activities. Additionally, three service designers supported and guided the core team. 
Case $\mathrm{C}$ focuses on environmental justice and climate resilience in a polycentric German region. The project's overall goal was to develop strategies for enhancing environmental justice and climate resilience at the regional, urban, and neighborhood level. RWLs were established at each level, partly in a multi-level setting. This paper is based on a multi-level RWL (at city and regional level) with a focus on housing policies. The core team consisted of five university researchers, two administrators of a regional development association, one municipal administrator, and temporarily further staff of both administrations as well as a cross-institutional working group of municipal housing representatives of the polycentric region.

Case D is a 3-year project with labs in two German neighborhoods. Planning and design researchers from two universities, two urban research and participation agencies, and two municipal planning offices work together in the core team. The research aims to transform administrative routines of citizen participation in urban development. It aims particularly to address city users with a migrant family background. While the municipal planning offices hope for (online and offline) technical and procedural tools to adapt participation procedures and settings to the needs of these target groups, the researchers search for multilingual and performative strategies to enhance motivation to participate both in terms of topics and process design. Several participation agencies support and facilitate the RWL interventions.

Each of the four real-world labs followed a different methodological design, producing a rich variety of empirical data like formal protocols, expert interviews, collective evaluation materials (e.g., feedback postcards, a structured evaluative email exchange and blog, evaluative interviews) as well as personal minutes and field notes. Based on this empirical data set, we, the authors of this article, collaboratively wrote the 'stories' for each of our (partly still ongoing) RWLs and identified key events, experiences and decisions related to the transdisciplinary cooperation in the lab teams. We then evaluated the narratives in an iterative collaborative process along different inductively and deductively defined categories. For this paper, we extracted all conflicts we attribute to different expectations and multiplicity of roles for academics, and clustered them, based on similarities such as timing, groups of actors involved, etc., in three ideal-typical situations that demonstrated how the above-mentioned challenges played out. In a last step, we collectively selected those conflicts that seemed to be paradigmatic for the three ideal-typical situations and condensed them in the vignettes presented in the following. The authors translated all quotes and narratives into English for the purpose of this article.

\section{Ambiguous roles and expectations: experiences from four RWL-based research projects}

In this section, we present three ideal-typical problem clusters to show how ambiguous roles and expectations came to the fore in our RWL settings. They played out differently in each project but seemed to have common roots. The first cluster shows how researchers need to find a strategic balance between conflict and consensus in situations they perceive as particularly sensitive and important for the future RWL cooperation: How much conflict can they risk, and how much do they have to accommodate the research partners' wishes so that transformation processes can continue? The second cluster reflects power struggles against the background of different rationales and routines of urban institutions, which come up in the organization of public RWL interventions: Who has the power of defining a situation, and who is likely to win or lose if anything goes wrong? The third cluster refers to different and ambiguous interpretations of 'successful' outcomes in lab projects at a point when strategic decisions need to be taken about the future directions of the project. We argue that initial negotiations and agreements are insufficient to avoid these types of conflict because of the experimental character of RWLs. This conclusion is supported by literature on team development, which we discuss afterwards.

\section{Consensus or conflict?}

The willingness to reach consensus is one of the most important requirements of transdisciplinary research. By consensus, we mean the effort to integrate different viewpoints and opinions into a synthesis (Defila and Di Giulio 2017) against the background of common (social) group norms (Scholz and Steiner 2015). A consensus is not only important at essential milestones but also in team meetings and daily interactions. The following vignettes illustrate situations when researchers need to compromise, because they consider not only what they think is 'right', but also the further cooperation in the project; they fill out the roles of reflective scientist, knowledge broker, and process facilitator at the same time:

An early core team meeting revealed the stereotypes and prejudices of one partner, member of a civil society organization, about migrants' relations to nature and their local environment. For example, he declared that their idea of cleanliness was decidedly different from 'Germans'. One researcher found these statements inacceptable and highly problematic, not least because they affected the partner's long-term volun- 
tary work and, consequently, were likely to have an impact on the planned lab interventions in 'deprived' neighborhoods with a high share of residents with a migratory background. However, the researcher did not see herself in a position to start an argument in a core team that was supposed to act at eye-level. Given the need to cooperate closely in the future and the wish to keep the goodwill and engagement of the partner, the researcher decided against the open conflict, even though she would have argued against it in another setting as a reflective scientist. (case A)

In our RWLs, scientists often had to assume the role of facilitator or mediator in consensus building, which made it difficult for them to contribute their scientific expertise. These different roles were at times incompatible, as the following vignettes shows:

Several lab workshops included stakeholders from outside the core team, who were invited to share their expertise only occasionally. Ideally, all stakeholders should have met at eye-level. Instead, the scientists were always assigned the facilitator role-partly due to lack of resources, partly because it was expected of them, and partly to be able to direct the discussion towards the research interest. Thus, they could not contribute with their scientific expertise as they could have if they had participated as reflective scientists or knowledge brokers. If moderating researchers had a substantive conflict of content as discussion parties, they were hardly able to solve the conflict if they remained in their role as facilitators and mediators. This sometimes led to a prioritization of political and tactical debates over debates on scientific findings. (cases B, C)

Working with only occasionally involved stakeholders also redefines relationships within a team, as they might bring new expectations, collaborative practices and lab objectives. To them, formerly agreed objectives and responsibilities can be unclear, particularly if team members have little experience in working together or if there is a lack of trust. Such constellations may complicate smooth 'performance' in the sense of a constructive and in-depth debate at eye level, which is needed to come to consensus. This illustrates that consensus building is strongly dependent on relationships and expectations within a team (Defila and Di Giulio 2017).

The need for a balance between consensual co-research and confrontation in a new group constellation became apparent in workshops in public administrations, intended as spaces for co-design and co-production. On the one hand, the core lab team wished to discuss the project topic openly at eye level. On the other hand, the core team members who came out of the administrations warned that their colleagues needed a wellstructured program with a clear purpose and learning benefit. Language was also an issue: the academics were instructed not to speak 'too academically' and to stay close to the experiences of the practitioners. The confrontation with practitioners' expectations put researchers into a rather defensive position. They had to demonstrate appreciation for the experiences of the practitioners, while the practitioners 'were themselves' and put little effort into the production of a synthesis in the sense of common knowledge production. (case D)

The experiences show that transdisciplinary teamwork, which values knowledge and contributions equally regardless of someone's professional training or institutional background, is not easy. This bears the risk that either the lowest common denominator prevails, or results will be incoherent.

\section{"Not with our logo": troubles with institutional logics and external communication}

All our labs aimed to develop a corporate identity with clear objectives. The symbol for this corporate identity was the RWL logo, which the teams developed to address external stakeholders and to stimulate co-design and co-production processes. However, the development of a project identity and the communication of the project and its results to a wider public are not an easy task. Struggles of meaning making, hierarchies and power (who has the say and ultimately determines what the project stands for?) and 'lab external' expectations (which 'institutional' regulations etc. are team members subjected to as part of a public administration, a planning office, etc.?) came up. Interestingly, these conflicts were often negotiated through — at first glance_-rather unimportant details, as the positioning of a logo in a publication:

For an initial RWL intervention, core team members from the public administration opened doors to their colleagues from the local urban development company (LUDC). The LUDC was interested to try out something 'different', so the lab decided to pool resources and co-organize the intervention so that everyone could pursue their goals and get something out of it. The LUDC even offered financial support for the print material to advertise the event. But their reaction to the professionally designed advertisement material was: 'This will not work: Our logo is always in that corner...' They were unwilling to abandon their corporate design standards, while design researchers were disappointed that their efforts and experience were not valued. To 'save' the common event, they did some changes to their original design, but as the LUDC did not show any readiness for give-and-take, the lab was 
split up in the end into two separate interventions at the same space and time. (case D)

This vignette shows that formal institutional requirements can become a barrier and potentially also put the whole team collaboration at risk. The following example demonstrates that the withdrawal of an institutional logo can also relate to dissatisfaction with research results:

When a core team member from a local body was confronted with scientific findings his institution did not agree with, he decided to attach a statement to the scientists' report to distance himself from these findings. The conflict could only be resolved when all partners agreed that joint results reports would only be used internally and not published with the common project logo. The conflict exacerbated further in the middle of the project when scientists presented preliminary results in a public presentation with the common logo, although all partners had not yet accepted them. Despite team-internal mediation, the incident severely affected the relationship of the partners for the rest of the project. (case C)

Power struggles within an RWL and 'lab external' expectations are not only revealed by the use and positioning of logos, but also by the use of a common language and activities associated with the joint RWL logo, as the following vignette shows:

In the first public citizens' workshop, team members from the local administration asked the scientists to avoid certain politically 'explosive' terms in connection with the main topic of the event for tactical reasons. The administrative staff hoped to prevent participants from expressing their objections to the topic which, they feared, would then become explosive. The scientists complied with this request because they did not want to jeopardize future cooperation. The politically explosive topic also affected a subsequent workshop series at the end of the project to which no public invitation was sent out to avoid media attention. The reasons were similar: the administrative partners intended to prevent citizens from using the opportunity to express their displeasure and thus dominate the events and provoke negative headlines. Based on earlier experiences, the administrative staff was worried that citizens would confuse the findings of a third-party funded lab with plans or programs of the participating city administration, and feared that they would be held responsible for the topics and content of such events. (case B)

To sum up: In transdisciplinary research aiming at urban transformation, a logo is not just a logo. Rather, a logo can be the starting point for team struggles regarding outward communication about the lab and its goals towards the local population and other stakeholders. As the vignettes indicate, an institutional logo symbolizes specific institutional values, norms, contents, etc. which are represented by different members of the lab team.

\section{Defining 'success' or 'failure' of lab results}

Agreeing on a common objective is an important prerequisite for smooth teamwork and for achieving results which satisfy everyone's expectations. In RWLs, the objectives necessarily remain vaguer and more open than in other research settings, and they have (at least) two dimensions: producing findings and new knowledge (research objectives) and initiating transformation processes (practice objectives) (Arnold and Piontek 2018; Beecroft et al. 2018). Strategies, experiments, and interventions remain subject to co-design and co-production processes that may bring surprises, unexpected findings or unintended side effects. These processes can change directions several times and lead to results different from those expected in the beginning:

The key challenges for climate resilience policies that researchers had identified after the first third of the project did not correspond to the perceptions and priorities of the administrative team members, who withdrew their support for further activities. Researchers were unable to continue their work, while institutional team members were disappointed and felt that they had contributed their knowledge, but the academics had failed to 'deliver' appropriate problem definitions and solutions. This affected the commitment to the project on all sides. It took some effort and time to find the lowest common denominator for developing strategies and measures during the remainder of the project. Many team members felt that the RWL had failed to exploit its full potential in several regards. (case C)

The vignette shows that team members are attached to the role and logic of their institution. They must meet expectations 'at home' in terms of the results or the timeframe in which expectations should be met. This is particularly true for those core team members who are temporarily employed for the purpose of the RWL and do not yet have an established 'standing' in the institution to stand up for RWL needs. They seek orientation for themselves within their institution, need to establish a position for themselves, and to be alert if they do not want to jeopardize further career ambitions within the institution once the RWL has terminated.

Scientists can potentially get something out of the project even if experiments 'fail' and findings do not correspond to the aimed-for results; they can learn from them and write about them (research objectives). However, criteria 
of academic excellence can be hard to meet in 'practiceoriented' or 'applied' projects such as RWLs. In contrast, partners from public administrations, civil society and urban politics expect rather concrete outcomes: technical tools, instruments for participation, process recommendations, references for other projects, access to certain networks, etc. (practical objectives). In the best case, all co-researchers benefit even if the outcomes do not meet their original expectations. But it may also be the case that partners will find their expectations disappointed and become resentful.

In one project, the expectations of core team members differed. One group of university researchers was interested in administrative settings, staff's attitudes and experiences, while another group tackled users' needs. In contrast, the team members from public administrations and planning agencies expected new tools for easy implementation into their routines and procedures. Last, but not least, civil society organizations hoped for more opportunities to voice their concerns. The lab team designed the interventions so that they would meet the different team members' expectations. However, it soon became clear that there can be no simple once-for-all solutions, but a whole range of factors needs to be reflected. These findings helped academics to think about the problem in new ways. Team members from public administrations, while appreciating the space for exchange and reflection the lab offered, nonetheless kept expressing their hope for concrete tools. (case D)

This vignette illustrates that expectations of team members are not always compatible, and that benefits for all cannot be achieved easily. The expectation to produce 'successful' solutions in the short term may conflict with an RWL ideal that is open to failure and with the need for more time which may be much more likely to lead to success (in a longer-term) (see Petroski 2013).

In sum, these three clusters show how ambiguous roles and expectations play out differently and impede a smooth lab performance in various ways. Building a transdisciplinary team for the negotiation and definition of roles and expectations is an important prerequisite for transdisciplinary cooperation in any RWL, as RWL literature argues (see "Challenges for RWLs in urban settings"). However, our vignettes show that this is easier said than done. Certain rules and objectives can be negotiated at the beginning. But it is the nature of RWL research that during the process of co-creation and co-production, topics and people come and go; priorities change over time, and new types of interventions are invented that could not be foreseen at the start, either in reaction to failure, unexpected outcomes or new team constellations. In the following, we discuss how literature on team development addresses these challenges and provides insights for the potentials of transdisciplinary RWLs for urban transformation.

\section{Discussion: organizing transdisciplinary teamwork in RWLs}

While the role of communication for successful transdisciplinary research can never be underestimated, our vignettes show that this may not be enough for 'unsettled' teams in RWL settings. RWLs require flexibility and the readiness to adapt the research process to new findings. A broad objective can be formulated in the beginning, but what exactly will be the outcome depends to some significant extent on the research process itself.

How does this flexibility affect team performance? According to Bruce Tuckman's model of 'developmental sequence in small groups' (1965), which has often been used for normative recommendations on 'good' teamwork (e.g., Stahl 2002), this presents a severe problem. Tuckman identifies four subsequent stages of group development:

(1) A 'forming' phase when group members seek to orientate themselves, test boundaries and development dependency relationships;

(2) A 'storming' phase when conflict and polarisation arise due to individual resistance to group influence and task requirements;

(3) A 'norming' phase when ingroup feeling and cohesiveness develop, the group agrees to common standards and adopts new roles; and

(4) A 'performing' phase when roles of group members become flexible and functional, and the groups' energy, supported by interpersonal structures, is directed towards task performance.

With reference to Tuckman, Stahl (2002, p. 55) claims that one stage must be terminated for the next one to begin, meaning that negotiations of collective norms for cooperation ('norming', stage 3), for example, will not be successful as long as the 'storming' stage (2) still goes on. He considers teamwork as 'perpetual motion machine' (Stahl 2002, p. 54) in the sense that the phases continue to follow each other in a potentially infinite process. This illustration corresponds to circular and cyclical models of RWLs, which also start with the 'forming' of transdisciplinary teams, but often fail to systematically address issues of team development 
afterwards. Accordingly, in adaptive RWL processes, with the involvement of different members at different times, the phases (1) and (2) may repeat over time, and teams might be unable to ever reach stages (3) and (4).

In contrast, Gersick (1988) stresses the importance of the halfway point for successful teamwork. According to her findings, many teams establish their framework for cooperation-roles, expectations, objectives, etc.—as early as during the very first meeting. From then on, 'repertoires of behavioural routines and performance strategies' are based on 'simplifying assumptions in order to take any action at all' (Gersick 1988, p. 33). Group members hang on to the original framework until halfway point, because until then they are unable to fully capture the meaning and relations of the data they have been gathering or the concepts they have been developing. At halfway points, teams make a midterm assessment - what has been reached, compared to what they want to achieve- and start understanding contextual requirements (Gersick 1988, p. 35), and ideally, they will reconsider and reorganize their framework (Gersick 1988, pp. 33-34). According to this 'phase model', a collective understanding of the task at hand is developed by those involved at the start, and they reassemble at midway point to wrap up what has been done and focus towards the end. In unsettled RWL teams, this likely works to some extent. However, not all team members may be there from the start, and be equally familiar with the framework. In that case, either the reorganization of the framework might lead to preliminary closure, or it may take up too much time so that it cannot realistically be implemented in the remaining time.

These models clarify that team development follows certain dynamics along ideal-typical stages or phases. As the vignettes showed, teamwork in RWLs cannot easily undergo the stages mentioned above in a regular order, and teams may consist of different team members in different lab phases. Moreover, the core team is not necessarily one that takes independent decisions. There are always 'others in the room', even if they are not present in person. Apart from the core team, the open research process of RWLs requires the involvement of different new (groups of) actors in the course of co-research. This makes it more difficult than in other research team settings to establish a team and come up with common norms and objectives. It is only against this background that team development in RWLs can be understood properly.

The confrontation with ambiguous roles and expectations may be an overwhelming experience for team members. For example, scientists are expected to recognize and act out the 'adequate' role in each situation, but they may be unable to fulfil these roles if they lack skills or resources. This shows that the need for external facilitation, mediation or team management and for an adequate institutional infrastructure is much greater in RWLs than in disciplinary research. We argue that transdisciplinary teams must be equipped with extra money and skills for team development to enhance their transformative capacity (Wolfram 2016). The fact that researchers might be forced, intentionally or not, to switch back and forth between different roles prevents them to focus on their 'original' roles as reflective scientist and knowledge brokers. This cannot always be communicated at the beginning of an RWL project as only the then developing dynamic reveals what a team requires. But particularly searching for transformation in the urban context requires this flexible situational adaptation of roles.

Furthermore, stakeholders from different institutional backgrounds might have diverging expectations. If knowledge and interests are not constantly synthesized, either the lowest common denominator prevails, or results will be incoherent. Consequently, it may be possible to define certain guiding principles for the process (in a 'norming' phase), but whether the lab will be seen as success or failure depends much more on the team members' perspectivesand on what is at stake for them in urban governance settings - than on 'objective' criteria. Both aspects, inherent to the circular RWL model, illustrate the specificity of the lab format between urban research and practice.

In sum, the results of the study at hand show that urban research in transdisciplinary teams is a fuzzy thing that makes RWLs different from other types of research exclusively undertaken by academics. We can see that in RWLs concerned with urban transformation, the research process is at the same time the research object, which needs constant reflection. Again, this stresses the need for institutional support. RWLs depend much more on 'extra-professional' skills of researchers than conventional research projects. These skills are acquired over time and thus correspond to age and experience of researchers. RWLs are valuable learning environments, but if all participants are supposed to benefit equally, individual and common experiences need to be reflected constantly and collectively. Often, RWLs do not have the time and the resources to undertake this kind of (self-)evaluations systematically. If the role of the (self-)reflexive scientist remains vacant, it is much harder to provide this kind of learning environment. We agree with Gaziulusoy et al. (2016, p. 63), who focus on transdisciplinary research in general terms, that ' $[t]$ ime required for team development and expanding both knowledge base and collaboration skills of research team members should be incorporated into project proposals to enable the research groups to become effective teams.'

All this makes our RWL experiences typical for transdisciplinary research in general: first and foremost, what comes to the fore is that it is a real challenge to put the conceptual demands into practice. Even if a transformative, co-creative research approach offers the chance to meet sustainability challenges more adequately then conventional research 
methods, this is easier said than done. This applies, e.g., to power asymmetries between different core team members that cannot be resolved despite a collaborative approach. However, what RWL research also shows is that it is worth looking at micro situations in detail to learn how to organize transdisciplinary research projects most successfully.

\section{Outlook: the potential of RWLs in transformative urban studies}

The recent crises that cities have been facing make new modes of transformative research necessary. In this study, taking four RWL projects in Germany as case studies, we examined obstacles to successful teamwork in RWLs. We conclude: first, that ambiguous roles and expectations are inevitably linked to transdisciplinary teamwork in circular RWL processes; second, that there cannot be any single strategy or tool to address them; third, that specific challenges in transdisciplinary RWLs can be met by systematic team building strategies. The strategic approach also helps to overcome possible challenging personal characteristics of team members, such as a lack of social skills or inexperience as facilitator or change agent. This requires resources and infrastructures, which must be taken into account in the initial phase of an RWL to be able to implement such a strategic approach during the cyclical research process. We argue that in particular the core team of the RWL and highly engaged stakeholders will benefit from these additional resources and infrastructures, whereas increased team building activities will probably have less impact on loosely connected stakeholders and actors 'behind the scenes' who indirectly bring their expectations and agenda to the RWL. Nevertheless, additional resources and infrastructure for strategic team building are exceedingly well invested in the core team, as its members represent the key drivers of the RWL. The fundamental need for additional resources and infrastructure to train members of inter- and transdisciplinary teams to collaborate effectively and more smoothly is also often emphasized by studies in the science of team science research field. Apart from that, approaches to solving the challenges we as academics have outlined also need to be examined specifically from the perspective of practitioners, who may suggest different approaches.

Based on our experience, we argue that RWLs have enormous potential for transformative urban research, but ambiguous roles and expectations in transdisciplinary 'unsettled' teams may challenge their success and transformative impact. A great advantage is that transdisciplinary RWL team members come from a variety of institutional and noninstitutional backgrounds and thus present - in a nutshellsmall communities of experts. They are not only able to identify and understand a specific urban problem, but also to find and test solutions (in niches/as 'showcases'/in specific urban contexts). They illustrate-and make it impossible to lose sight of - the social construction of knowledge, which has great transformative potential for research. RWLs allow researchers to (practice to) become change agents for urban transformation. While the results of lab research are-at first sight-only applicable to a certain context and thus rather small-scale, knowledge production through co-design and co-production generates broader understandings of how to come to strategies and solutions and how to implement them. For example, a transferability to different urban contexts can be promoted by extracting generic process-related factors. Comparative and feasibility studies can provide further insights into the transferability of transformative impacts (Luederitz et al. 2017). Such research helps to overcome the risk of staying within methodological localism and nationalism and instead understand cities' multitude of social, environmental, and economic problems as entangled on multiple scales and RWLs as one tool to address these challenges in all their complexity.

Acknowledgments We are very grateful to our colleagues, co-researchers and research partners from the RWLs INTERPART, iSCAPE, KoopLab and ZUKUR for the very fruitful and inspiring cooperation. We also thank two anonymous reviewers for their valuable comments to an earlier version of this article.

Funding Open Access funding enabled and organized by Projekt DEAL. This article is based on research in four RWL projects, funded by the German Federal Ministery of Education and Research (funding agreements 01UM1822AY, 01UR1706A, 01LR1721A) and by the European Union's Horizon 2020 research and innovation programme (grant 689954).

Open Access This article is licensed under a Creative Commons Attribution 4.0 International License, which permits use, sharing, adaptation, distribution and reproduction in any medium or format, as long as you give appropriate credit to the original author(s) and the source, provide a link to the Creative Commons licence, and indicate if changes were made. The images or other third party material in this article are included in the article's Creative Commons licence, unless indicated otherwise in a credit line to the material. If material is not included in the article's Creative Commons licence and your intended use is not permitted by statutory regulation or exceeds the permitted use, you will need to obtain permission directly from the copyright holder. To view a copy of this licence, visit http://creativecommons.org/licenses/by/4.0/.

\section{References}

Arnold A, Piontek FM (2018) Zentrale Begriffe im Kontext der Reallaborforschung. In: Defila R, Di Giulio A (eds) Transdisziplinär und transformativ forschen: Eine Methodensammlung. Springer VS, Wiesbaden, pp 143-154

Beecroft R, Trenks H, Rhodius R, Benighaus C, Parodi O (2018) Reallabore als Rahmen transformativer und transdisziplinärer Forschung: Ziele und Designprinzipien. In: Defila R, Di Giulio 
A (eds) Transdisziplinär und transformativ forschen: Eine Methodensammlung. Springer VS, Wiesbaden, pp 75-100

Börner K, Contractor N, Falk-Krzesinski HJ, Fiore SM, Hall KL, Keyton J, Spring B, Stokols D, Trochim W, Uzzi B (2010) A multi-level systems perspective for the science of team science. Sci Trans Med 2:49cm24. https://doi.org/10.1126/scitranslmed. 3001399

Brown VA, Deane PM, Harris JA, Russell JY (2010) Towards a just and sustainable future. In: Brown VA, Harris JA, Russell JY (eds) Tackling wicked problems: through the transdisciplinary imagination. Earthscan, Abingdon, Oxon, UK, pp 3-15

Bulkeley H, Simon M, Yuliya V, McCormick K, Breitfluss-Loidl M, Mai L, von Wirth T, Frantzeskaki N (2019) Urban living laboratories: conducting the experimental city? Eur Urban Regional Stud 26:317-335. https://doi.org/10.1177/0969776418787222

Defila R, Di Giulio A (2017) Managing consensus in inter- and transdisciplinary teams: tasks and expertise. In: Frodeman R, Klein JT, Pacheco RCdS (eds) The Oxford handbook of interdisciplinarity. Oxford University Press, Oxford, pp 332-337

Engels A, Walz K (2018) Dealing with multi-perspectivity in realworld laboratories: experiences from the transdisciplinary research project Urban Transformation Laboratories. GAIA - Ecological Perspectives for Science and Society 27:39-45. https://doi. org/10.14512/gaia.27.s1.10

Fricke W (2014) Aktionsforschung in schwierigen Zeiten. In: Jostmeier M, Georg A, Jacobsen H (eds) Sozialen Wandel gestalten: Dortmunder Beiträge zur Sozialforschung. Springer VS, Wiesbaden, pp 212-236

Gaziulusoy AI, Ryan C, McGrail S, Chandler P, Twomey P (2016) Identifying and addressing challenges faced by transdisciplinary research teams in climate change research. J Clean Prod 123:5564. https://doi.org/10.1016/j.jclepro.2015.08.049

Gersick C (1988) Time and transition in work teams: towards a new model of group development. Acad Manag J 31:9-41. https://doi. org/10.2307/256496

Hilger A, Rose M, Wanner M (2018) Changing faces - factors influencing the roles of researchers in real-world laboratories. GAIA - Ecological Perspectives for Science and Society 27:138-145. https://doi.org/10.14512/gaia.27.1.9

Kajikawa Y (2008) Research core and framework of sustainability science. Sustain Sci 3:215-239. https://doi.org/10.1007/ s11625-008-0053-1

Kanning H (2018) Reallabore aus planerischer Perspektive. sustainify Arbeits- und Diskussionspapier 3, Sustainify, Hanover

Karvonen A, van Heur B (2014) Urban laboratories: experiments in reworking cities. Int J Urban Reg Res 38:379-392. https://doi.org/ 10.1111/1468-2427.12075

Kemmis S, McTaggart R (2005) Participatory action research. In: Denzin NK, Lincoln YS (eds) Handbook of qualitative research. Sage Publications, Thousand Oaks, CA, pp 559-603

Luederitz C, Schäpke N, Wiek A, Lang D, Bergmann M, Bos J, Burch S, Davies A, Evans J, König A (2017) Learning through evaluation-a tentative evaluative scheme for sustainability transition experiments. J Clean Prod 169:61-76. https://doi.org/10.1016/j. jclepro.2016.09.005

Miller TR (2013) Constructing sustainability science: emerging perspectives and research trajectories. Sustain Sci 8:279-293. https:// doi.org/10.1007/s11625-012-0180-6

Nowotny H, Scott P, Gibbons M (2011) ReThinking science: knowledge and the public in an age of uncertainty. Blackwell Publishers, Oxford

Nyström A-G, Leminen S, Westerlund M, Kortelainen M (2014) Actor roles and role patterns influencing innovation in living labs. Ind Mark Manage 43:483-495. https://doi.org/10.1016/j.indmarman. 2013.12 .016
Ozanne JL, Saatcioglu B (2008) Participatory action research. J Consumer Res 35:423-439. https://doi.org/10.1086/586911

Padmanabhan M (2017) Introduction. In: Padmanabhan M (ed) Transdisciplinary research and sustainability. Routledge, London, pp $1-32$

Petroski H (2013) Success through failure: The paradox of design. Princeton University Press, Princeton

Pohl C, Rist S, Zimmermann A, Fry P, Gurung GS, Schneider F, Speranza CI, Kiteme B, Boillat S, Serrano E, Hirsch Hadorn G, Wiesmann U (2010) Researchers' roles in knowledge co-production: experience from sustainability research in Kenya, Switzerland, Bolivia and Nepal. Sci Public Policy 37:267-281. https://doi.org/ 10.3152/030234210x496628

Renn O (2018) Real-world laboratories - the road to transdisciplinary research? GAIA Ecological Perspectives for Science and Society 27:1

Rogga S, Zscheischler J, Gaasch N (2018) How much of the real-world laboratory is hidden in current transdisciplinary research? GAIA Ecological Perspectives for Science and Society 27:18-22. https:// doi.org/10.14512/gaia.27.s1.6

Saunders D (2010) Arrival city: how the largest migration in history is reshaping our world. Pantheon Books, New York

Schäpke N, Stelzer F, Bergmann M, Singer-Brodowski M, Wanner M, Caniglia G, Lang DJ (2017) Reallabore im Kontext transformativer Forschung. Ansatzpunkte zur Konzeption und Einbettung in den internationalen Forschungsstand. IETSR Discussion papers in Transdisciplinary Sustainability Research, Leuphana Universität, Lüneburg

Schäpke N, Stezler F, Caniglia G, Bergmann M, Wanner M, SingerBrodowski M, Loorbach D, Olsson P, Baedeker C, Lang DJ (2018) Jointly experimenting for transformation? Shaping realworld laboratories by comparing them. GAIA Ecological Perspectives for Science and Society 27:85-96. https://doi.org/10.14512/ gaia.27.s1.16

Schneidewind U (2014) Urbane Reallabore - ein Blick in die aktuelle Forschungswerkstatt. In pndlonline III/2014. Retrieved June 18, 2020, from http://archiv.planung-neu-denken.de/fre-ausgabenmainmenu-63.html

Scholl C, Kemp R (2016) City labs as vehicles for innovation in urban planning processes. Urban Planning 1:89-102. https://doi.org/10. 17645/up.v1i4.749

Scholz RW, Steiner G (2015) The real type and ideal type of transdisciplinary processes: part I-theoretical foundations. Sustain Sci 10:527-544. https://doi.org/10.1007/s11625-015-0327-3

Seebacher A, Alcántara S, Quint A (2018) Akteure in Reallaboren - Reallabore als Akteure. In: Defila R, Di Giulio A (eds) Transdisziplinär und transformativ forschen. Eine Methodensammlung, Springer VS, Wiesbaden, pp 155-159

Sieber R, Gülleken L (2018) ZUKUR stellt sich vor. Lecture at a kickoff workshop in the ZUKUR neighbourhood office. 16 May 2018. Unpublished. Dortmund

Singer-Brodowski M, Wanner M, Schneidewind U (2017) Real-world laboratories as an institutionalisation of the new social contract between science and society. In: Padmanabhan M (ed) Transdisciplinary research and sustainability. Routledge, London, pp 53-65

Stahl E (2002) Dynamik in Gruppen. Beltz PVU, Weinheim

Stoecker R (1999) Are academics irrelevant? Am Behav Sci 42:840854. https://doi.org/10.1177/00027649921954561

Stokols D, Hall K, Taylor BK, Moser RP (2008) The science of team science: overview of the field and introduction to the supplement. Am J Prev Med 35:77-89. https://doi.org/10.1016/j.amepre.2008. 05.002

Thomas EJ, Rothman J (2013) Intervention research: design and development for human service. Taylor and Francis, Hoboken

Tuckman B (1965) Developmental sequence in small groups. Psychol Bull 63:384-399. https://doi.org/10.1037/h0022100 
von Unger H (2014) Partizipative Forschung: Einführung in die Forschungspraxis. Springer, Wiesbaden

Wanner M, Hilger A, Westerkowski J, Rose M, Stelzer F, Schäpke N (2018) Towards a cyclical concept of real-world laboratories. disP the Planning Review 54:94-114. https://doi.org/10.1080/02513 625.2018.1487651

Wiek A, Farioli F, Fukushi K, Yarime M (2012) Sustainability science: bridging the gap between science and society. Sustain Sci 7:1-4. https://doi.org/10.1007/s11625-011-0154-0

Wittmayer JM, Schäpke N (2014) Action, research and participation: roles of researchers in sustainability transitions. Sustain Sci 9:483-496. https://doi.org/10.1007/s11625-014-0258-4

Wittmayer JM, Avelino F, van Steenbergen F, Loorbach D (2017) Actor roles in transition: insights from sociological perspectives.
Environ Innov Soc Trans 24:45-56. https://doi.org/10.1016/j.eist. 2016.10 .003

Wolfram M (2016) Conceptualizing urban transformative capacity: a framework for research and policy. Cities 51:121-130. https://doi. org/10.1016/j.cities.2015.11.011

Publisher's Note Springer Nature remains neutral with regard to jurisdictional claims in published maps and institutional affiliations. 